\title{
Program Enhancement: Responding to the Call for Special Education Teachers to be Highly Qualified
}

\author{
Tachelle Banks*
}

Cleveland State University, 2121 Euclid Ave., JH 307, 44115, USA

\begin{abstract}
The alignment of No Child Left Behind (NCLB) and Individuals with Disabilities Education Act (IDEA) 2004 states that special education teachers are expected to have content area expertise in every content area that they teach and for which they are the teacher of record. The academic content requirements put in place by NCLB and IDEA have created the need to rethink pre-service education for special educators. This article will describe higher education efforts to improve special education teacher training and ultimately the educational experiences for students with exceptionalities. In addition, a brief description of the efforts of an institution of higher education (IHE) in northeast Ohio to better prepare preservice special education teacher candidates to meet highly qualified teacher (HQT) standards by enhancing their current intervention specialist high incidence program will be provided.
\end{abstract}

Keywords: Teacher quality, highly qualified teachers, special education.

\section{INTRODUCTION}

The No Child Left Behind Act (NCLB) and the Individuals with Disabilities Educational Improvement Act (IDEA) requires all schools and districts show that all students are achieving at proficient levels - as defined by the state, in the areas of reading and math by 2013-2014 [1]. Moreover, educational agencies are responsible for showing that they are making adequate yearly progress (AYP). This means that K-12 teachers, general and special education, must be fully licensed by the state and cannot have an emergency, temporary or provisional certification; must have a bachelor's degree; or must have passed a rigorous standardized state test. Secondary teachers are held to the same standards with the expectation of being able to pass a rigorous state test in the subjects that they teach or have completed an academic major in the area that they teach.

Because of changes in the field, specifically the impact of NCLB and defining expectations of being "highly qualified" specified in IDEA for special educators, many states and higher education programs will have to revise, extend, or completely change teacher education programs. In particular, special education programs will have to figure out what programmatic issues need to be addressed in an effort to produce special education teachers who will graduate meeting the criterion to be "highly qualified" in subjects that they will teach. Revised special education teacher education programs must reflect the need for today's special educators to be knowledgeable about and extensively prepared to teach students with high-incidence disabilities (e.g. learning disabilities (LD), emotional behavior disorders (EBD), mild intellectual disabilities (MID), and attention deficit hyperactive disorders (ADD/ADHD) in a wide range of

*Address correspondence to this author at the Cleveland State University, 2121 Euclid Ave., JH 307, 44115, USA; Tel: 216-687-4608;

E-mail: t.i.banks@csuohio.edu settings and in concert with a number of other professionals as well as family members.

\section{IDENTIFYING GAPS \& WEAKNESSES IN SPECIAL EDUCATION TEACHER PREPARATION PROGRAMS}

NCLB requires increased accountability for states, local school districts, and schools. Schools who fail to meet adequate yearly progress (AYP) are subject to measures aimed at getting them back on track. NCLB also emphasizes using scientifically based programs and instructional methods while clearly stating that all teachers need to be highly qualified in content related classes that they teach. IDEA 2004 states that highly qualified special education teacher has the same meaning as it does for elementary and secondary teachers with the exception that special educators must also obtain full state licensure as a special education teacher. As a result of the alignment of these legislations, today all states require teachers, including special educators, to demonstrate some level of subject matter competency.

There is considerable research showing how important teachers' content knowledge is to their effectiveness with students. Darling-Hammond (1998) [2] argued that teachers need to understand subject matter deeply and flexibly. This kind of understanding provides a foundation for pedagogical content knowledge that enables teachers to make information accessible to others. Consequently, the argument seems to be that special education teacher candidates would be better teachers if subject matter is deemed more important in special education teacher preparation programs. Moreover, special education teacher candidates would be more qualified to teach content because they have the subject matter knowledge.

Many special education teachers currently being prepared to teach at middle and high school levels, do not meet the HQT requirements as set forth in NCLB and IDEA [3]. In essence, discrete special education teacher preparation 
programs, have trained teacher candidates for years without subject-matter expertise or substantial content knowledge. These identified needs calls for an enhancement of current special education licensure programs to prepare special education teacher candidates who serve students with mildmoderate needs to teach academic content in the areas of math, science, social sciences, and English/language arts.

Reviews of research in both general and special education suggested that subject-matter knowledge is important for teachers, particularly those in secondary education [4]. Many states offer a K-12 Special Education credential. This means that pre-service programs must prepare their candidates to teach in both the elementary and the secondary school settings. The lack of certainty regarding the grade levels pre-service teachers will be teaching when they graduate, and the amount of coursework and time required to prepare teachers in every academic content area appear to be the greatest barriers hindering preparation of secondary special education teachers.

While enrollments of students in special education programs are increasing, inadequately prepared special education teachers are still graduating from teacher education programs without meeting the HQT standards. This has often led to children with special learning needs in some regions being educated by teachers (a) with temporary special education certification (e.g., teacher has elementary education certification), or (b) whose certification is in an area other than that required to serve the children they teach (e.g., a teacher with moderate-severe certification teaching students with mild disabilities), or (c) with no formal education training or certification [3].

\section{SPECIAL EDUCATION TEACHERS \& HQT}

NCLB requires all core academic classes to be taught by teachers who are "highly qualified" according the law's definition. This generally means they must have a bachelor's degree, be fully certified, and demonstrate their knowledge and skills in the subjects they teach by having sufficient subjectmatter coursework, passing a state test, or meeting other state criteria. NCLB also requires states to ensure that low-income and minority students are not taught by inexperienced, unqualified, or out-of-field teachers at higher rates than other children. Together, these teacher requirements were viewed by the law's sponsors as critical steps in improving student achievement. Special education teachers are the group that poses the greatest challenge to meeting the highly qualified requirements. According to the Center on Educational Policy (2007) [5], eighty-three percent of states and forty-seven percent of districts reported having problems complying with the highly qualified requirements for special education teachers. The following sections will discuss common features of effective teacher education programs that can serve as a basis for the enhancement process, and will illustrate the enhancement of a Special Education program at an institute of higher education (IHE) in northeast Ohio to assist preservice teachers with meeting HQT standards.

\section{RESTRUCTURING SPECIAL EDUCATION TEA- CHER PREPARATION PROGRAMS}

Restructuring of teacher preparation programs has been widely recommended as a means to better prepare preservice special and general educators for inclusive settings. Restructuring strategies should include content knowledge, inclusive methodologies, instructional and curricular accommodations, functional behavioral assessment, collaborative skills, and knowledge of assistive technologies for both special and general education preservice teachers [614].

Upon review of the literature, several programs have offered their insights with regard to program development, revision, or extension to meet the standards set forth by NCLB and IDEA. Brownell, Ross, Colon, and McCallum (2003) [15] conducted an analysis of effective teacher education programs. The researchers noted that while it was difficult to define effective teacher education that generalized across programs they were able to establish a conceptual framework that operationalized characteristics of effective practices in teacher education. Across the two studies, seven common features of effective teacher education programs emerged. Brownell et al. (2003) [15] suggested that all effective teacher education programs have common features including (a) coherent program vision that provides faculty with a common language to communicate with others across all coursework and field experiences; (b) blended theory that consists of disciplinary knowledge and subject specific pedagogical knowledge and practice; (c) carefully crafted field experiences that should be extensive, integrate well with coursework, developmental and carefully supervised; (d) standards of quality; (e) active pedagogy that require faculty to establish and monitor strategies from high admission standards to stringent exit criteria; (f) pedagogy that addresses issues of diversity in courses, assignments and field experiences; and ( $\mathrm{g}$ ) collaboration as a vehicle for building a professional community was a common feature in effective teacher education programs.

Brownell et al. (2003) [15] concluded that teacher education program descriptions included strong programmatic vision and a heavy emphasis on subject-matter pedagogy (e.g., reading, mathematics, and science). With regard to special education, some program descriptions articulated a clear vision, whereas others did not [15]. Exemplary programs in general teacher education also placed heavy emphasis on subject matter knowledge, whereas special education programs tended to focus more on pedagogy (e.g., instructional methods, assessment, individualized education plans) [15]. Their findings provide a basis for evaluating teacher education programs, both general and special education.

At one end of the continuum are initiatives in which distinct programs for special and general educators have been melded into a "unified" teacher preparation program in which all teacher candidates undertake an expanded program designed to meet the guidelines and standards for both special and general education certifications [10, 12]. Although unified programs are viewed as an ideal model for teacher preparation [7-9], unified programs may never achieve large-scale adoption because of potential barriers such as cost, disincentives to extend the length and requirements of undergraduate programs, and both human and institutional resistance to dramatic changes in the structure of colleges of education and individual teacher preparation programs. 
A more prevalent initiative to improve teacher preparation involves what may be called "enhancement" of existing programs by adding new courses or field experiences, or by revising the content and requirements for existing courses or experiences for special and/or general education programs [13]. Program enhancements may also involve the creation of shared, even collaborative, experiences for special and general education preservice teachers [6]. Infusion of content into existing classes has also been used to enhance the preparation of general education teacher candidates [16]. Therefore, program enhancements that create shared courses and field experiences may be more effective than those that provide content on collaborative skills without opportunities to practice collaboration.

\section{OHIO'S APPROACH TO SPECIAL EDUCATION TEACHER PREPARATION PROGRAM ENHANCE- MENT}

Ohio is taking an innovative approach to improve services and results for children with disabilities resulting in a reciprocal relationship and close collaboration between Ohio's IHEs and the Ohio Department of Education (ODE). Several IHEs in Ohio are partnering with ODE as members of the Ohio Consortium to Improve the Teaching of Students with Disabilities. The Consortium was created because Ohio views the redesign of special education teacher preparation as systemic, closely tied to state licensure for preservice training and integrally embedded in inservice professional development. By collaborating with IHEs, the ODE is sharing the responsibility for improving special education preservice training to better ensure that new special education teachers are able to meet HQT requirements upon graduation and are employable.

The Consortium is voluntary and consists of ODE and 28 IHEs representing the central and northeast, northwest, southeast, and southwest quadrants of the state. The Consortium IHEs comprise both public and private institutions, large and small institutions, and institutions with a variety of missions. The goal of the Consortium is for the work of IHEs and ODE to become more integrated and interdependent, capitalizing on the strengths of each to reach the common goal of what is best for students. The Consortium is innovative in that Ohio has developed a framework for the State Educational Agency (SEA) and IHEs to become a close knit community of learners and practitioners, combining finite fiscal and human resources to support the improvement of instruction for special education teacher preparation. The Consortium plays an integral role in the redesign of the preparation and licensure structure of Ohio's future special educators to ensure that all students receive high-quality instruction from well-prepared teachers (M. Lehman, personal communication, September 2, 2008).

As a participating IHE of the Ohio Consortium, an institution in northeast Ohio has developed and implemented enhanced program components. The following discussion describes their fully funded enhancement model that is informed by the literature base [15] that suggests that special education programs should place more importance on programmatic vision and increased focus subject-matter knowledge and produce teachers that should be able to demonstrate their knowledge of content. In other words, special education teacher preparation programs should produce teachers that know what they are teaching and know how to teach subject matter to students with exceptionalities.

For example, in Ohio new special educators can obtain elementary HQT by passing the Praxis II Introduction to the Teaching of Reading test. This exam also furnishes new teachers, grades 7-12 Special Education, HQT for English Language Arts and Reading. To earn HQT for grades 7-12 in additional content areas, Ohio requires new teachers to either take 30 semester hours in the related subject matter area, or to pass the corresponding Praxis II Middle School content area exam. Currently the institution has in place a 12 credit hour series of literacy courses that are required by the state of Ohio and has now required that first licensure majors pass the Introduction to the Teaching of Reading Praxis II exam to earn HQT status for Elementary Special Education and grades 7-12 Special Education English Language Arts and Reading. This model has been extended to other subject matter areas to maintain a reasonable number of credits in our pre-service training programs. More importantly the identified courses will prepare Intervention Specialist to teach subject matter knowledge and prepare teacher candidates to pass the corresponding Praxis II exams to obtain HQT status in Ohio.

In collaboration with general education faculty special education faculty have identified a cadre of courses for mathematics, science, and social studies. For example, the mathematics series will consist of 4 courses, approximately 16 semester hours that can also be applied to general education requirements. In conjunction with the courses, students will be advised to take the Middle Childhood Content Praxis II to then hold Special Education 7-12 HQT for the Mathematics content area. This model appears to meet the need of the students enrolled in the special education programs and the IHE by (1) preparing special education teachers that know their content as indicated by a taking a series of content courses and passing the respective state exam to earn HQT status, (2) maintaining the quality of special education and integrating relevant content knowledge, (3) maintaining the current standard of approximately 5 years to earn a bachelor's degree by keeping credit hours at a reasonable number for students, and (4) producing teachers who know their content and pedagogy necessary to teach students with exceptionalities.

In addition to integrating content to help teacher candidates meet HQT standards upon graduation, student supports have been enhanced to assist students with their success in the Mild/Moderate program. The purposes of the enhanced student supports are to better recruit and retain students, particularly those from underrepresented groups and to better assist students in the preparation of passing national licensure exams. For example, online virtual learning communities that focus on special education content, principles of teaching and learning, mathematics and test taking strategies have been developed, piloted and implemented for all Special Education teacher candidates. Students engage in a self-review of materials that reinforces content learned in their course work and test taking strategies. In addition, group orientation sessions have been designed and implemented that provide basic information about the program and introduce faculty as mentors and role 
models for students. Finally, development of an informal peer-mentoring program that will pair new students in the program with students who have been in the program (for at least one year) to familiarize students with the program and university life, etc., is underway.

To enhance the use of evidence-based strategies (EBS) by first licensure special education teacher candidates a curriculum alignment process has begun by modifying the Mild/Moderate teacher preparation curriculum. Emphasis is placed on the use of EBS throughout courses in a consistent and coordinated fashion. For example, integration of the IRIS modules, a professional development website for special education professionals, were included in courses and specific evidenced based strategies (EBS) and activities be covered in all mild/moderate courses by both full and parttime faculty to ensure that EBS are taught and practiced consistently throughout the program. Additional supports for all faculties are in place to encourage consistent information sharing that is accurate and up to date. Full time and part time faculty participate in informational meetings related to program enhancement efforts, have access to the special education faculty website that houses curricular information that will support the teaching and assessment of EBS. EBS reference materials are distributed regularly and all faculty have participated in the program syllabi review and enhancement process.

To bridge the gap between theory and practice regarding the use of research-based practices, we are requiring student mastery of key EBS as assessed through course assignments and field experiences. We have modified and require hallmark assignments that monitor the mastery of key EBS throughout the curriculum. In addition, field syllabi and field evaluation forms have been enhanced to require mastery demonstration of EBS. To date special education preservice teacher candidates have participated in a paired student teaching experience with general education teacher candidates to begin familiarizing students with the practice of inclusion and ensuring collaborative experiences between prospective special education and general education teacher candidates. Future plans include the development and implementation of field assessment procedures that will monitor the demonstration of "teaming" skill use and mastery.

The enhanced model also includes the provision of teacher induction support for the use of EBS and collaborative work with general educators to graduating first licensure, high incidence special education teachers. Two options were designed including support, a one-credit course option for teacher induction each semester and electronic support option, to all first licensure special education teacher candidates through their first and second years of teaching. In sum, the enhanced program will offer coursework and field experiences that are designed to provide increased content knowledge, the use of EBS and collaboration between general and special educators. The following section will discuss the design of the enhanced program in relation to what the literature describes as an effective teacher education program.

Brownell's et al. (2003) [15] description of effective teacher education programs will serve as a basis for discussion of our enhancement efforts. The enhanced model was developed with a coherent program vision that provides faculty with a common language to communicate with others across all coursework and field experiences as training for part time faculty and special education supervisors is an integral part of the enhancement process. Course work and field experiences are aligned to provide knowledge, skill attainment and practice of EBS throughout out the program. Monitoring of EBS in field placements will be enhanced as field observation documentation will be updated to align with knowledge attainment and mastery of EBS. Collaboration with general education teacher candidates is a feature that is currently being piloted and will be built in collaboration with Office of Field Services as part of the enhanced special education program requirement. Disciplinary knowledge, subject specific pedagogical knowledge and practice will be improved by the development of content course packages that will provide subject matter knowledge while maintaining standards of quality as an accredited program. Finally, the program will continue to provide pedagogy that addresses issues of diversity in courses, assignments and field experiences.

In sum, special education programs will be enhanced by ensuring that subject matter knowledge is obtained, EBS are integrated in every course via curriculum alignment and implementing shared field experiences between general and special educators. These program enhancements are informed by the literature and ensure student practice of content and specific pedagogy while meeting requirements for HQT status in the State of Ohio. Consequently, students who graduate from the enhanced special education program will know what they are teaching; will know how to teach content to students with exceptionalities and will graduate highly qualified to teach academic content that extends beyond passing a state exam.

\section{CRAFTING A SPECIAL EDUCATION TEACHER PREPARATION RESEARCH AGENDA}

Suggestions on improving special education teacher education programs have been offered by various researchers $[2,4,11,15,17,18]$. According to McLesky \& Ross (2004) [4], researchers need to determine the valued outcomes of teacher education and how we assess these outcomes. HQT has been previously defined in the literature as the acquisition of content knowledge, which for some states is measured by test scores, or accumulation of credit hours or professional development contact hours.

Second, researchers need to determine how preparation programs make a difference. Currently, teacher education programs include knowledge of validated practices and that meet some of the criteria for high-quality teachers. Although the link between evidence-based practice and student achievement exists, no research exists to show that including this knowledge in teacher preparation programs or including specific teacher education program components make a difference in outcomes for special education teachers, and more important, for their students with disabilities. In the future, research needs to examine these critical connections.

Third, we need to understand how opportunities to acquire subject-matter knowledge influence special education practice. Research in general teacher education, although inconclusive, suggested that teachers with subject- 
matter preparation achieve better student outcomes than graduates who lack that preparation [4]. In the International Reading Association (IRA) study, teachers extensively prepared in literacy achieved stronger student literacy achievement gains than other beginning teachers, but they did not feel more prepared to teach mathematics [19]. Until this point, conversations about subject- matter learning have not figured prominently in research studies of special education teachers. Instead, special education researchers have assumed that effective special education teachers are those who implement validated interventions. But can special education teachers implement validated interventions for individual students without a deep understanding of the content? Furthermore, how does academic performance of students develop in relation to the teachers' content knowledge base?

\section{CONCLUSION}

Major competencies in the enhancement of Cleveland State University's current special education program include (a) content knowledge, (b) integration of EBS, (c) knowledge of and practice of EBS in course work and field experience and (d) knowledge and practice of collaborative and teaming skills. Included in the planning phase is collaboration with general education faculty to (1) determine the appropriateness of the content related courses, (2) build potential partnerships with school districts and related agencies, (3) develop content for the HQT and EBS seminars for faculty and supervisors, (4) revise and implement an induction and professional development component for beginning special education teachers, (5) carefully plan field experiences in conjunction to relevant courses and to make the experience a collaborative effort between general and special education preservice students, (6) review current course content to ensure that EBS are being provided and (7) devise a plan to measure effectiveness of the enhanced program.

\section{CONFLICT OF INTEREST}

The author confirms that this article content has no conflict of interest.

\section{ACKNOWLEDGEMENT}

Required Edgar Statement: The contents of this manuscript were developed under a grant from the Department of Education. However, the contents do not necessarily represent the policy of the Department of Education, and you should not assume endorsement by the Federal Government.

\section{REFERENCES}

[1] Henley M, Ramsey RS, Algozzine RF. Characteristics of and strategies for teaching students with mild disabilities. Upper Saddle River, NJ: Pearson Education, Inc. 2009.

[2] Darling-Hammond L. Teacher learning that supports student learning. Educ Leadersh 1998; 55(5): 6-11.

[3] Quigney TA. The status of special education teachers at the secondary level: effects of the highly qualified teacher standard. Am Second Educ 2009; 37(2): 49-61.

[4] McLesky J, Ross DD. The politics of teacher education in the new millennium: Implications for special education teacher educators. Teach Educ Spec Educ 2004; 27(4): 342-9.

[5] Center on Education Policy. Implementing the no child left behind teacher requirements. Washington, DC: From the Capital to the Classroom: Year 5 of the No Child Left Behind Act 2007; p. 41.

[6] Beloin K, Peterson M. For richer or poorer: Building inclusive schools in poor urban and rural communities. Int $\mathrm{J}$ of Disabil Dev Educ 2000; 47(1): 15-24.

[7] Benner SM, Judge, SL. Teacher preparation for inclusive settings: A talent development model. Teach Educ Quart 2000; 27(3): 2338.

[8] Blanton LP, Sindelar PT. Models and measures of beginning teacher quality. J Spec Educ 2006; 40(2): 115-27.

[9] Hinders K. Dual certification and the regular education initiative. J Teach Educ 1995; 46(3): 200-8.

[10] Jenkins AA, Pateman B, Black RS. Partnerships for dual preparation in elementary, secondary, and special education programs. Rem Spec Educ 2002; 23(6): 359-71.

[11] Lovingfoss D, Molloy DE, Harris KR, Graham S. Preparation, practice and program reform: Crafting the University of Maryland's five-year, multicategorical, undergraduate program in special education. J Spec Educ 2001; 35(2): 105-14.

[12] Pugach MC, Seidl BL. From exclusion to inclusion in urban schools: A new case for teacher education reform. Educ Urban Soc 1995; 27(4): 379-96.

[13] Strawderman C, Lindsey P. Keeping up with the times: Reform in teacher education. J Teach Educ 1995; 46(2): 95-100.

[14] Van Laarhoven TR, Muck DD, Lynch K, Bosma J, Rouse J. A model for preparing special and general education preservice teachers for inclusive education. J Teach Educ 2007; 58(5): 440-55.

[15] Brownell MT, Ross DR, Colon EP, McCallum CL. Critical features of special education teacher preparation: A comparison with exemplary practices in general teacher education. Gainesville, FL: Center on Personnel Studies in Special Education 2003.

[16] Cook BG. Inclusive attitudes, strengths, and weaknesses of preservice general educators enrolled in a curriculum infusion teacher preparation program. Teach Educ Spec Educ 2002; 25(3): 262-77.

[17] Barnett B. What it means to be a highly qualified teacher. Chapel Hill (NC): University of North Carolina; 2002; Report No.: SP 014 708.

[18] Blake C, Monahan EC. Rethinking teacher preparation for EBD students: Towards a partnership model. Brit J Learn Support 2007; 22(2): 60-5.

[19] Flint AS, Fine J, Maloch B. Trends in teacher certification and literacy: "I just feel like I'm ready": Exploring the influence of quality teacher preparation on beginning teachers. Read Teach 2002; 56(4): 348-50. 